\title{
Foundations of Science
}

24 de octubre 2019. Vol. 25, N. ${ }^{\circ}$.

\section{The Third Construct of the Universe: Information}

\author{
C. Barreiro · Jose M. Barreiro · J. A. Lara · D. Lizcano · M. A. Martínez · J. Pazos.
}

\author{
Foundations of Science, Vol. 25, N. 2 \\ DOI: 10.1007/s 10699-019-09630-7 \\ ISSN I233-182I
}

\section{RESUMEN:}

Very few scientists today question the fact that information, together with matter and energy, is one of the three constructs forming the ontology of the universe. However, there is still a long way to go before in order to establish the interrelations between informa-tion and energy and information and matter, as Einstein did between matter and energy. In this paper, after introducing the energy, matter, information (IME) model, which covers the three constructs and their relationships, we illustrate real examples - two qualitative and two quantitative - of the interrelations between energy and information. This closes the open question with respect to the interrelationship between energy and information.

\section{PALABRAS CLAVE:}

Energy, IME model, Information science, Information theory, Matter. 